CARRETA, Jorge Augusto. A ceroplastia e a medicina legal na Faculdade de Medicina da Universidade de São Paulo, 1934-1950. História, Ciências, Saúde Manguinhos, Rio de Janeiro, v.23, n.3, jul.-set. 2016, p.757-777.

\title{
Resumo
}

\section{A ceroplastia e a medicina legal na Faculdade de Medicina da Universidade de São Paulo, 1934-1950}

\author{
Ceroplastics and forensic \\ medicine at the Faculty of \\ Medicine, Universidade de \\ São Paulo, 1934-1950
}

Jorge Augusto Carreta

Professor, Faculdade de Ciências Econômicas/Faculdades de Campinas. Estrada Municipal Unicamp-Telebrás km 1, s.n. - Cidade Universitária 13083-970 - Campinas - SP - Brasil

jorgecarreta@yahoo.com.br
$\mathrm{O}$ artigo busca investigar as relações entre a ceroplastia e a institucionalização da disciplina de medicina legal na Faculdade de Medicina da Universidade de São Paulo. As peças em cera, representando doenças ou partes do corpo que seriam objeto da perícia médico-legal, foram produzidas por Augusto Esteves entre 1936 e 1960 Supõe-se que a produção ceroplástica representou o programa traçado por Flamínio Fávero, catedrático de medicina legal entre 1923 e 1955 . A comparação entre as peças de cera do acervo do Museu Técnico-científico do Instituto Oscar Freire e o tratado de medicina legal de Fávero, publicado pela primeira vez em 1938, indica que tal suposição é plausível.

Palavras-chave: ceroplastia; medicina legal; história da medicina; Faculdade de Medicina de São Paulo; Augusto Esteves (1891-1966).

Abstract

This article investigates the relationships between ceroplastics and the institutionalization of forensic medicine as a discipline at the Faculty of Medicine, Universidade de São Paulo, Brazil. The wax models, representing diseases or body parts that were the subject of medical forensic investigation, were produced by Augusto Esteves between 1936 and 1960. It is believed that the ceroplastic production represented the program devised by Flaminio Fávero, full professor of forensic medicine between 1923 and 1955. The comparison between the wax pieces at Museu Técnico-Científico (a science and technology museum) at Instituto Oscar Freire and the treatise on forensic medicine by Fávero, first published in 1938 , indicates that such a supposition is plausible.

Keywords: ceroplastics; forensic medicine; history of medicine; Faculty of Medicine of São Paulo; Augusto Esteves (1891-1966). 
$\mathrm{C}^{\circ}$ omo indica Monteiro (2009), a preocupação com a representação do corpo humano e desvendamento de suas estruturas íntimas são componentes marcantes da cultura visual ocidental, sobretudo com o surgimento da chamada ciência moderna. Especificamente durante o Renascimento, quando há o resgate dos estudos anatômicos, as investigações sobre os mistérios do corpo não eram feitas apenas pelos médicos, mas também por artistas preocupados em representar a figura humana da maneira mais fidedigna possível (Landes, 2008).

A modelagem em cera estava inserida no movimento maior de mudança nas formas de conhecimento anatômico. Não há precisão quanto ao período em que modelos de cera foram usados para o ensino ou preparação de médicos. Modelos em cera do corpo humano ou de suas partes são produzidos desde há quatro mil anos. Podem-se encontrar peças feitas por egípcios, gregos e romanos (Haviland, Parish, 1970). O uso de imagens votivas, que representam partes do corpo curadas pela graça de santos ou da divindade, data desde os períodos pré-cristãos e até hoje podem ser encontradas nas igrejas. Em Florença, dos séculos XIII ao XVII, eram inúmeros os ateliês que produziam tais imagens.

Conforme mencionado, o interesse científico pela exploração do interior do corpo ressurgiu durante o Renascimento, mobilizando médicos e artistas. Havia grandes dificuldades para conseguir cadáveres e preservá-los. Muitas vezes os anatomistas eram acusados de manter ligações com criminosos que roubavam corpos recém-sepultados de cemitérios. ${ }^{1}$ Maneiras de preservação das peças anatômicas pelo maior tempo possível foram desenvolvidas; ainda assim, esse tempo era limitado. ${ }^{2}$ A modelagem em cera foi a saída para reproduzir os órgãos e estruturas internas. O material era facilmente moldado, poderia ser colorido e receber implantes orgânicos para aumentar seu efeito de representação (pelos, cabelos, dentes etc.) (Ballestriero, 2009). Para os cirurgiões, os modelos em cera poderiam suprir a falta de cadáveres usados em demonstrações anatômicas.

Entre fins do século XVII e começo do XVIII, o interesse por modelos de cera dentro da profissão médica atinge seu auge, com destaque para a produção feita por cirurgiões, tal como o francês Guillame Desnoues (1650-1735). Utilizando-se da técnica de injeção de cera nas preparações, ele organizou em Paris um museu de peças anatômicas de cera aberto à visitação pública. As peças também foram expostas em Londres e atraíram grande atenção. Antes de alugar as peças para fins didáticos, o médico francês preferiu fazer um tour por cidades do interior da França e Inglaterra. Em 1726, as peças reaparecem em anúncios de palestras sobre anatomia humana (Haviland, Parish, 1970).

O surgimento da modelagem médica de doenças (chamada de moulage, termo derivado do francês mouler, que significa "moldar") seguiu o desenvolvimento da anatomia patológica e de novas noções sobre saúde e doença. O início desse processo pode ser localizado em meados do século XIX, mas desde o século XVII encontram-se esforços de descrição e classificação das enfermidades que acometiam os seres humanos (Sevalho, 1993, p.357). O médico inglês Thomas Sydeham (1624-1689) dizia que "para ajudar o doente era preciso delimitar e determinar o seu mal" (Canguilhem, 2007, p.11). Haveria, segundo ele, espécies mórbidas, tal como existem as espécies vegetais ou animais.

O médico italiano Giovanni Battista Morgagni (1682-1771) criou a anatomia patológica por meio da associação entre as lesões presentes em tecidos corporais e os sintomas de certas 
doenças, permitindo que a classificação nosográfica encontrasse, como disse Canguilhem (2007, p.12), apoio na "decomposição anatômica".

Essa identificação entre lesão histológica e doença abriu caminho para a evolução da fisiologia. François Broussais (1772-1838), combinando elementos das doutrinas de Xavier Bichat e John Brown, defendia a ideia de que as doenças eram de natureza quantitativa, isto é, surgiriam devido a uma maior ou menor excitação dos órgãos ou tecidos do corpo. O excesso de estímulos, provenientes do meio ou do próprio cérebro, teria mais importância que a falta e daí decorreria a maioria dos estados patológicos. Nessa concepção, a patologia era um prolongamento da fisiologia. Saúde e doença, normal e patológico apresentariam uma relação de continuidade, seriam apenas a variação numérica de um mesmo estado. O corolário dessa concepção é a doença como algo visível, tangível e mensurável. ${ }^{3}$ Essa teoria foi assumida e continuada por Claude Bernard (1813-1878), o grande nome da medicina experimental francesa.

Para Bernard, a medicina experimental compreendia três partes distintas: a fisiologia, a patologia e a terapêutica, sendo a primeira sua base. Ele considerava a medicina de sua época essencialmente empírica. Apesar de apontar as limitações dessa prática médica, Bernard não a rejeitava, mas afirmava que a observação era parte importante da medicina experimental. Dentro de seu esquema de evolução das ciências, exposto em Introdução ao estudo da medicina experimental, publicado em 1865, a medicina empírica era o primeiro período da medicina experimental. Mas todos os dados oriundos da observação deveriam ser submetidos à prova pela experimentação. Em sua época, dizia Bernard (1944, p.266-268), a medicina se encontraria em uma fase de transição do empirismo puro para a observação combinada à experimentação laboratorial.

Tal maneira de pensar o patológico vai se opor à clínica, conjunto de formulações médicas oriundas da observação dos sintomas clínicos dos doentes feitas à beira dos leitos (Foucault, 2006). Essa medicina "racionalista" deu origem ao que se chamou de concepção ontológica de doença, isto é, aquela que considerava que todos os males tinham sua própria "história natural" e podiam ser ordenados em classes, ordens, gêneros e espécies (Sevalho, 1993, p.357). Foucault (2006, p.139) observa que "a clínica, olhar neutro sobre as manifestações, frequências e cronologia, preocupada em estabelecer parentesco entre sintomas e compreender sua linguagem, era ... estranha a essa investigação de corpos mudos e atemporais ... Anatomia e clínica não têm o mesmo espírito".

No entanto, essa oposição vai aos poucos enfraquecendo e surge no século XIX aquilo que Foucault chamou de "anatomoclínica", resultante de uma "litigiosa estruturação" na qual a clínica e a anatomia patológica se confrontaram. A clínica e sua nosografia ganharam uma nova base proveniente da anatomia patológica de Xavier Bichat (1771-1802), que privilegiava a análise dos tecidos formadores do corpo, e não dos órgãos (Foucault, 2006). ${ }^{4}$

Os modelos em cera, inicialmente, buscavam representar de forma fidedigna a anatomia humana e traduzir as leis naturais. Porém, desde o artista siciliano Zumbo podemos perceber a preocupação com a doença e a decadência do corpo. ${ }^{5}$ A moulage se torna relevante no começo do século XIX. Conforme aponta Schnalke (1995, p.47), ela acompanhou as mudanças que transformaram a medicina em uma disciplina clinicamente orientada. 
Da metade do século XIX em diante, as especialidades médicas começavam a se multiplicar, impulsionadas pelo avanço das técnicas cirúrgicas, do diagnóstico clínico mais apurado e da experimentação. A dermatologia e a venereologia se tornaram disciplinas médicas reconhecidas no início do século XIX, separando-se de outras (Haviland, Parish, 1970, p.69). Sua origem, entretanto, está na anatomia patológica do final do século anterior (Schnalke, 1992). Inicialmente, a anatomia patológica desenvolveu a noção de que as doenças estavam associadas a um órgão específico. Com isso, a prática clínica ganhou ênfase, com a observação do doente e a descrição dos sintomas. Os diagnósticos eram confirmados pelas dissecções. Essas práticas identificaram novas doenças e as classificaram em sistemas nosológicos. Os grupos se relacionavam com os órgãos e seus sistemas, o que serviu de base para o surgimento das especialidades médicas (Schnalke, 1992, p.134).

A pele humana não era vista como um órgão, e suas afecções apenas refletiriam a doença de órgãos internos. Aos poucos, essa concepção mudou, e ela passou a ser vista como local de condições patológicas específicas, que poderiam ser descritas e tratadas. Por volta de 1860, como indicam Haviland e Parish (1970), a dermatologia ainda fazia parte das disciplinas médicas iniciantes, e seus praticantes começaram a perceber a importância dos modelos de cera para fins didáticos. ${ }^{6}$

Foi no Hôpital Saint Louis, em Paris, que ocorreu o Primeiro Congresso Internacional de Dermatologia e Sifiliologia, em 1889. Segundo Schnalke (1992), esse evento marcou o início do período de florescimento da arte da moldagem na Europa. A instituição francesa teve papel central na consolidação da disciplina e a influenciou até meados do século XX.

A prática do "ensino do olho" (teaching of the eye) no Saint Louis já estava presente nas aulas do médico Jean Louis Alibert (1768-1837), que lançava mão de ilustrações, gravuras, aquarelas e pinturas a óleo para melhor caracterizar para seus alunos as doenças dermatológicas. Isso abriu caminho para a introdução da moldagem em cera no ensino do hospital, o que foi feito por Charles Lailler (1828-1898) na década de 1860. Seu principal colaborador foi Pierre François Baretta (1834-1923), artista de origem belga, contratado pelo Saint Louis em 1870. Ele produziu aproximadamente duas mil peças para o hospital, mas também para médicos particulares da França e de outros países. Além disso, foi o principal colaborador do Museu de Patologia do Saint Louis (Schnalke, 1992, p.135). ${ }^{7}$

O Primeiro Congresso Internacional de Dermatologia e Sifiliologia colocou em evidência as obras de Beretta, que foram vistas por médicos de diversas partes da Europa, despertando o interesse de formar coleções em seus próprios hospitais. ${ }^{8}$ A moldagem dermatológica restringiase aos grandes centros e ainda não era utilizada na Alemanha ou no Império Austro-húngaro. O evento parisiense certamente teve importância decisiva para a disseminação dessa técnica.

A moulage teve seu apogeu nas quatro primeiras décadas do século XX e conheceu sua decadência a partir da década de 1950. As peças, usadas no ensino, educação pública e pesquisa perderam força face ao surgimento de novas tecnologias de documentação e representação das doenças. ${ }^{9}$ Muitas coleções foram descartadas ou armazenadas de forma inadequada. A profissão de modelador médico foi extinta, e as técnicas, esquecidas. 


\section{A ceroplastia na Faculdade de Medicina da Universidade de São Paulo}

Entre 1920 e 1930, como assinalam Mota e Schraiber (2009, p.347), deu-se início a um conjunto de transformações corporativas vinculadas à formação dos médicos e suas especialidades, no qual o pensamento clínico conquistava mais espaço no que tocava às questões médicas e de saúde pública. Sob influência da Fundação Rockefeller, um novo modelo de ensino foi introduzido na Faculdade de Medicina de São Paulo (FMUSP). ${ }^{10}$ Também é importante situar esse processo em meio ao colapso da medicina liberal (Schraiber, 1993), modelo caracterizado pelo trabalho artesanal e desenvolvido no consultório privado. Seguindo as mudanças promovidas na política de saúde após 1930 e marcadas pela centralização, surgiu a figura do médico assalariado e ganhou força a discussão sobre as especialidades médicas. (Mota, Schraiber, 2009, p.351).

Armou-se o embate entre a "nova" e a "velha" medicina: os novos médicos teriam esquecido o passado heroico da profissão e não estariam interessados em seus reais problemas. Outro antagonismo que surgiu no período era aquele entre os "antigos generalistas" e os "novos especialistas". Como mostram Mota e Schraiber (2009, p.352), esse confronto "explicitava as mudanças de um profissional de conhecimento integral ao novo profissional, mais técnico e específico, apto às demandas tecnoassistenciais de acesso à assistência médica nos centros urbanos e rurais e com novas formas de produção social de serviços". O trabalho médico incorporava-se gradativamente ao Estado nos anos 1930, e, nesse contexto, as áreas médicas lutavam para estabelecer sua autonomia e seus objetos de intervenção. Segundo Gabriela Marinho (2001), no caso de São Paulo, a especialidade foi exigida como forma de possibilitar políticas no campo da pesquisa, da clínica e das organizações profiláticas, que demandavam profissionais com tratamento específico.

Foi nesse contexto que surgiu a ceroplastia na FMUSP, graças aos esforços dos professores João de Aguiar Pupo (1890-1980) e Flamínio Fávero (1895-1982), responsáveis, respectivamente, pelas cátedras de dermatologia e sifiligrafia e medicina legal (Sampaio, Lacaz, Azulay, 1980, p.213). ${ }^{11}$ O responsável pela confecção das peças foi Augusto Esteves (1891-1966), artista quase autodidata cuja carreira de modelador se iniciou com Vital Brazil no Instituto Butantan, em 1912. ${ }^{12}$ Ele também havia trabalhado como desenhista e ilustrador no Instituto Pinheiros. ${ }^{13}$

Esteves foi contratado em 1934 e ocupou inicialmente uma sala conseguida por Aguiar Pupo na Santa Casa de Misericórdia. Entre 1943 e 1959, foi auxiliar técnico da Clínica Dermatológica, contratado pelo mesmo professor. Nesse período, dedicou-se intensamente à moulage dermatológica, produzindo aproximadamente 260 peças (Lacaz, 1993).

Além de trabalhar para a cadeira de dermatologia e sifiligrafia, Esteves também atuou no Instituto Oscar Freire (IOF) sob a supervisão de Flamínio Fávero. Ele foi admitido no IOF em 1937 e produziu 38 peças representando himens, esgorjamentos, lesões por armas brancas ou de fogo, cicatrizes e acidentes de trabalho (Lacaz, 1993). ${ }^{14}$ Nos anos 1930, a dermatologia e a medicina legal eram cadeiras ainda recentes e lutavam para obter seu reconhecimento e definir seus objetos e campos de atuação. Neste artigo trataremos especificamente da produção de Augusto Esteves para a disciplina de medicina legal.

O primeiro titular da cadeira de medicina legal da Faculdade de Medicina de São Paulo foi o médico baiano Oscar Freire de Carvalho, profundamente influenciado pelas ideias de 
Raimundo Nina Rodrigues, expoente da medicina legal na Faculdade de Medicina da Bahia (Meira, Battistella, 2012).${ }^{15}$ As atividades da cátedra de medicina legal em São Paulo se iniciaram em 1918, e, paralelamente, Freire esforçou-se para construir o campo dessa disciplina por meio da fundação, em 1921, da Sociedade de Medicina Legal e Criminologia. A sociedade organizou conferências sobre a medicina legal, além de publicar a revista Arquivos da Sociedade de Medicina Legal e Criminologia de São Paulo, entre 1922 e 1959. ${ }^{16}$ Freire faleceu em 1923, e a cátedra foi assumida por seu discípulo Flamínio Fávero, que levou adiante a tarefa de consolidar o ensino e a pesquisa no campo da medicina legal paulista.

De acordo com Ferla (2009, p.65), a medicina legal dos anos 1920 e 1930 era bastante abrangente, reunindo disciplinas diferentes, tais como identificação médico-legal e identificação judiciária, tanatologia, traumatologia, noções de polícia técnica, criminologia, hematologia, infortunística (que trata dos acidentes de trabalho), sexologia, medicina profissional e deontologia (ou ética médica). Esse "programa" da medicina legal do período pode ser encontrado na volumosa obra de Flamínio Fávero (1958), sobretudo em Medicina legal, livrotexto escrito para ser usado no ensino da cadeira de medicina legal, publicado pela primeira vez em 1938. ${ }^{17}$

A ambição de ser uma "ciência moral", no sentido de fornecer orientações para o comportamento de modo a evitar a anomia, foi assumida pela medicina legal (Antunes, 1999, p.18). Podemos constatá-la na definição dada por Fávero (1958, p.10; destaque no original) à medicina legal em seu tratado:

É inegável que esta disciplina, dentro principalmente do subsídio dos conhecimentos médicos, embora já incorpore outros, tem finalidade mais extensa, mais vasta, de ação social. Assim, não mais atua, apenas, no esclarecimento de certas questões de processo civil ou criminal, nem tampouco, somente em aplicações forenses. Hoje a medicina legal age ou deve agir pela 'aplicação dos conhecimentos médicos biológicos na elaboração e execução de leis que deles carecem'.

Fávero buscava o "conteúdo original" da medicina legal, ou seja, o conhecimento e as questões próprias da disciplina, que escapariam às demais especialidades. A medicina legal não poderia ser "individualizada", isto é, ter suas questões resolvidas por qualquer especialista versado em tema específico. Se assim fosse, um cirurgião poderia dar seu parecer sobre um ferimento ou o ginecologista sobre questões sexuais. A essa "corrente restritiva" sobre a medicina legal, opor-se-ia a "corrente ampliativa", que defendia que a especialidade deveria ter método, objeto e objetivo próprios, exclusivos do médico legista (Fávero, 1958, p.11).

Fávero também se encarregou de fazer a história da especialidade, definindo as fases pelas quais a medicina legal brasileira teria passado. Partindo dos escritos de Oscar Freire, a quem sucedeu na cátedra de medicina legal na Faculdade de Medicina, o autor indica três fases da disciplina: a estrangeira, a de formação e nacionalização e a de consolidação da nacionalização. A primeira, que se estende de 1832 a 1877, caracteriza-se pela ausência de observação e experimentação feitas no Brasil. Os trabalhos nacionais seriam apenas "compilações servis da medicina legal francesa" (Fávero, 1958, p.17).

O segundo momento da evolução da medicina legal começou com a admissão de Agostinho José de Souza Lima na Faculdade de Medicina do Rio de Janeiro, a partir de 1877. Incluindo o trabalho de laboratório entre as atividades didáticas, Souza Lima teria dado um caráter 
prático ao ensino. O primeiro curso prático de tanatologia no Brasil foi dado por ele em 1881. Embora ainda se servindo de dados estrangeiros, diz Fávero que Souza Lima preocupou-se em comentar as leis brasileiras pelo prisma da medicina legal. Seus muitos trabalhos levantaram as questões importantes para a especialidade, despertando o interesse de médicos e juristas brasileiros por ela.

A terceira fase, a de nacionalização efetiva da medicina legal, refere-se aos trabalhos originais produzidos entre nós. Por isso se entenda estudos alicerçados na realidade nacional, nos temas e problemas próprios do país. Para Fávero, o baiano Nina Rodrigues é o inaugurador desse período, que se iniciou em fins do século XIX. Sua contribuição principal foi a coleta de dados clínicos e de laboratório para a solução de problemas médicos legais e de criminologia brasileiros. Em criminologia estabeleceu que o ponto de partida seria o estudo das "origens étnicas" das populações brasileiras. As contribuições estrangeiras não deveriam ser ignoradas, mas sempre confrontadas com a realidade de nosso meio físico, biológico e psicológico (Fávero, 1958, p.18-19).

Esse histórico vai terminar, naturalmente, com Oscar Freire, discípulo de Nina Rodrigues e mestre de Flamínio Fávero. Tendo atuado na Bahia e em São Paulo, a Oscar Freire é atribuído o papel de continuador da obra de Nina Rodrigues e de inaugurador da medicina legal paulista. Em 1918, ele foi nomeado por Arnaldo Vieira de Carvalho para cátedra de medicina legal da Faculdade de Medicina de São Paulo e iniciou o "ensino científico da medicina legal, lançando as bases de um grande centro de pesquisas" (Fávero, 1958, p.20).

O problema dessa classificação, como bem indica Antunes (1999), é a necessidade de Fávero afirmar a escola paulista por meio da desvalorização dos períodos anteriores. Vemos, então, a impossibilidade de enquadrar o desenvolvimento da medicina legal em esquemas predefinidos. ${ }^{18} \mathrm{O}$ histórico traçado por Fávero deve ser entendido como uma estratégia para consolidar a especialidade. O passado "incompleto", os primórdios especulativos, não científicos e eminentemente estrangeiros são um contraponto para afirmar a especialidade dos tempos de Fávero: uma medicina legal verdadeiramente científica, vazada no molde do método experimental, e, sobretudo, nacional.

Embora se esforçando para definir o escopo de sua especialidade, Fávero defendia paralelamente a importância da presença da medicina legal no currículo médico, ou seja, obrigatória para todos os alunos de medicina. Em memorial dirigido ao Conselho TécnicoAdministrativo da FMUSP, datado de 10 de outubro de 1940, ele defendia essa interessante posição. Afirmava que a medicina legal não era uma especialidade, alvo de estudos facultativos ou em separado, mas algo que deveria constar da formação obrigatória de todo médico: "Todo médico tem a obrigação de ser perito" (Fávero, 10 out. 1940). A perícia deveria ser exercida não apenas nos casos criminais, mas também nos de acidentes de trabalho. Para ele, a medicina legal era perícia. Por isso teria nascido e se desenvolvido.

Segundo Ferla (2005), a medicina legal no Brasil do entreguerras era fortemente influenciada pela biotipologia, derivada do pensamento de Cesare Lombroso. De acordo com essa corrente de pensamento, o ato antissocial era um tipo de patologia, e caberia à medicina legal identificá-lo, tratá-lo e também o prevenir. Com isso, a medicina legal, especialidade ainda em fase de consolidação, procurava definir seu campo de atuação, identificando seus objetos e métodos de abordagem. ${ }^{19}$ Ela reivindicava o "direito de examinar", ou seja, o 
exame médico seria a maneira de isolar os desvios e anomalias que constituiriam ameaça ao equilíbrio social (Ferla, 2005).

Contudo, além disso, o "direito de examinar" vinculava-se ao esforço para constituição do âmbito da especialidade. O trabalho de perícia deveria pertencer exclusivamente ao perito médico-legal. Como vimos acima, Flamínio Fávero foi um dos defensores dessa causa.

Essa preocupação com o rigor do trabalho pericial, aliado ao uso das técnicas laboratoriais, aponta para uma medicina legal que caminhava para a profissionalização e buscava obter reconhecimento por meio da demonstração de sua capacidade técnico-científica. Como assinala Antunes (1999, p.32), a medicina legal abandonou paulatinamente os "fatos morais", e a atenção dos médicos-legistas voltou-se para os aspectos técnicos das perícias.

As peças em cera produzidas por Augusto Esteves compuseram essa estratégia de fortalecimento técnico da atividade pericial e de delimitação dos objetos e métodos de intervenção da medicina legal paulista. Seguindo o livro-texto de Flamínio Fávero (1958), podemos verificar que a ceroplastia de Augusto Esteves deu concretude ao "programa" proposto por aquele médico para a medicina legal paulista. Quase todos os temas foram abrangidos, sem esgotá-los, pela ceroplastia. Apenas a hematologia, a criminologia, a psicopatologia, a medicina profissional e a ética médica não foram contempladas, por tratar de questões eminentemente teóricas. O resto, porém, ganhou forma por meio da ceroplastia. Sigamos, por meio da cera, os temas propostos por Flamínio Fávero. ${ }^{20}$

\section{Traumatologia e perícia médica}

Antunes (1999), ao enumerar as grandes questões médico-legais do Brasil, afirma que a importância da identificação dos cadáveres e a determinação da causa da morte tornaramse questões prementes após o caso de João Alves Castro Malta, em 1884. Acusado de ser

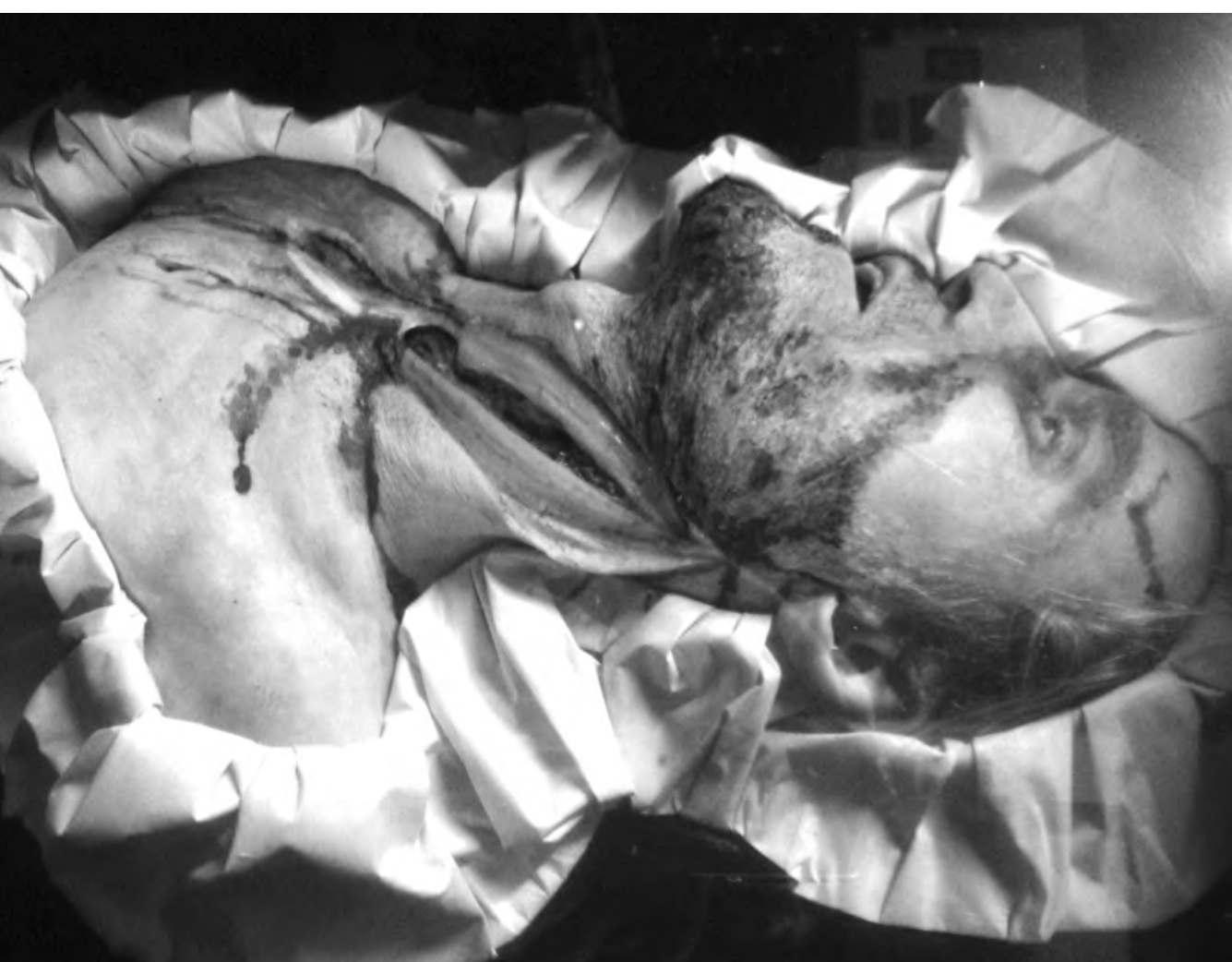

Figura 1: Estigma profissional do agressor caracterizado por tipo de lesão na vítima; caso de esgorjamento homicida. Agressor: funcionário de matadouro (Museu Técnicocientífico do Instituto Oscar Freire/FMUSP; foto do autor) 
capoeirista, Malta foi preso pela polícia e, ao chegar à Casa de Detenção, faleceu. O corpo foi enterrado sem autópsia, o que gerou indignação da família e polêmica na imprensa.

Os temas da Primeira Conferência Paulista de Medicina Legal e Criminologia de São Paulo e as peças de cera representando esgorjamentos, ferimentos por projéteis de arma de fogo e envenenamentos indicam que essa preocupação com a qualidade da perícia médica ainda estava viva nas primeiras décadas do século XX.

A primeira peça selecionada evidencia a preocupação com as autópsias e a identificação da arma do crime e, consequentemente, do criminoso. A perícia bem conduzida auxiliaria a elucidação do crime (Figura 1).

A perícia também poderia identificar as lesões causadas em órgãos internos por envenenamento, seja em casos de homicídio ou suicídio (Figura 2).

A atenção também era dirigida para os ferimentos causados por balas e instrumentos perfurocortantes. A perícia poderia determinar com precisão a arma do crime (Figuras 3 e 4).

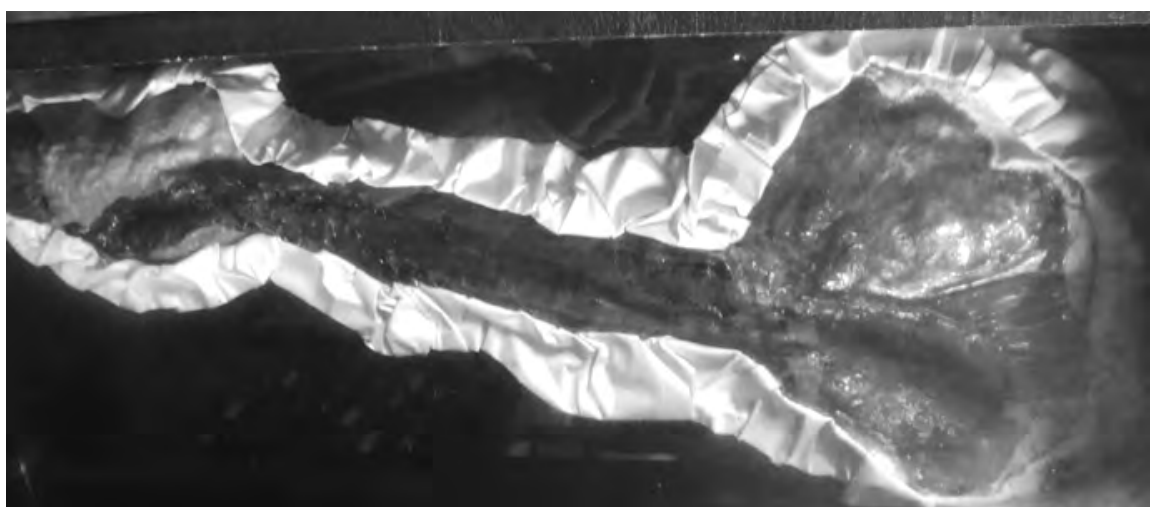

Figura 2:

Intoxicação com

soda; aspecto

de necrose da

orofaringe, do

esôfago e do

estômago (Museu

Técnico-científico

do Instituto Oscar Freire/FMUSP;

foto do autor)

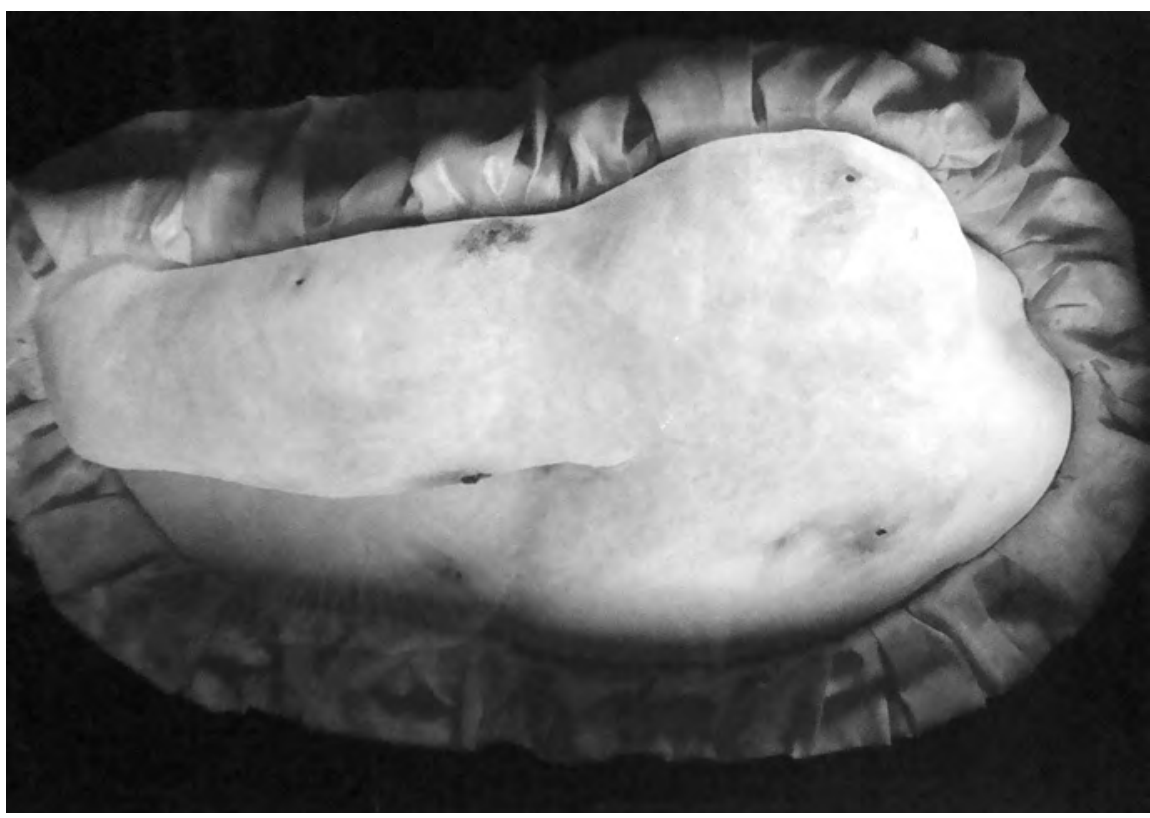

Figura 3: Caixa sem descrição, possivelmente ferimentos causados por projéteis de arma de fogo (Museu Técnico-científico do Instituto Oscar Freire/FMUSP; foto do autor) 
A identificação judiciária refere-se aos métodos para a identificação dos indivíduos por meio da fotografia, antropometria, datiloscopia, impressões palmares (mãos) e plantares (pés), de modo a permitir que a polícia identifique autores de crimes por meio dessas características corporais. As imagens a seguir mostram peças em cera (três em cada caixa) retratando as palmas e punho de uma mulher (Figura 7) e de um homem (Figura 8).

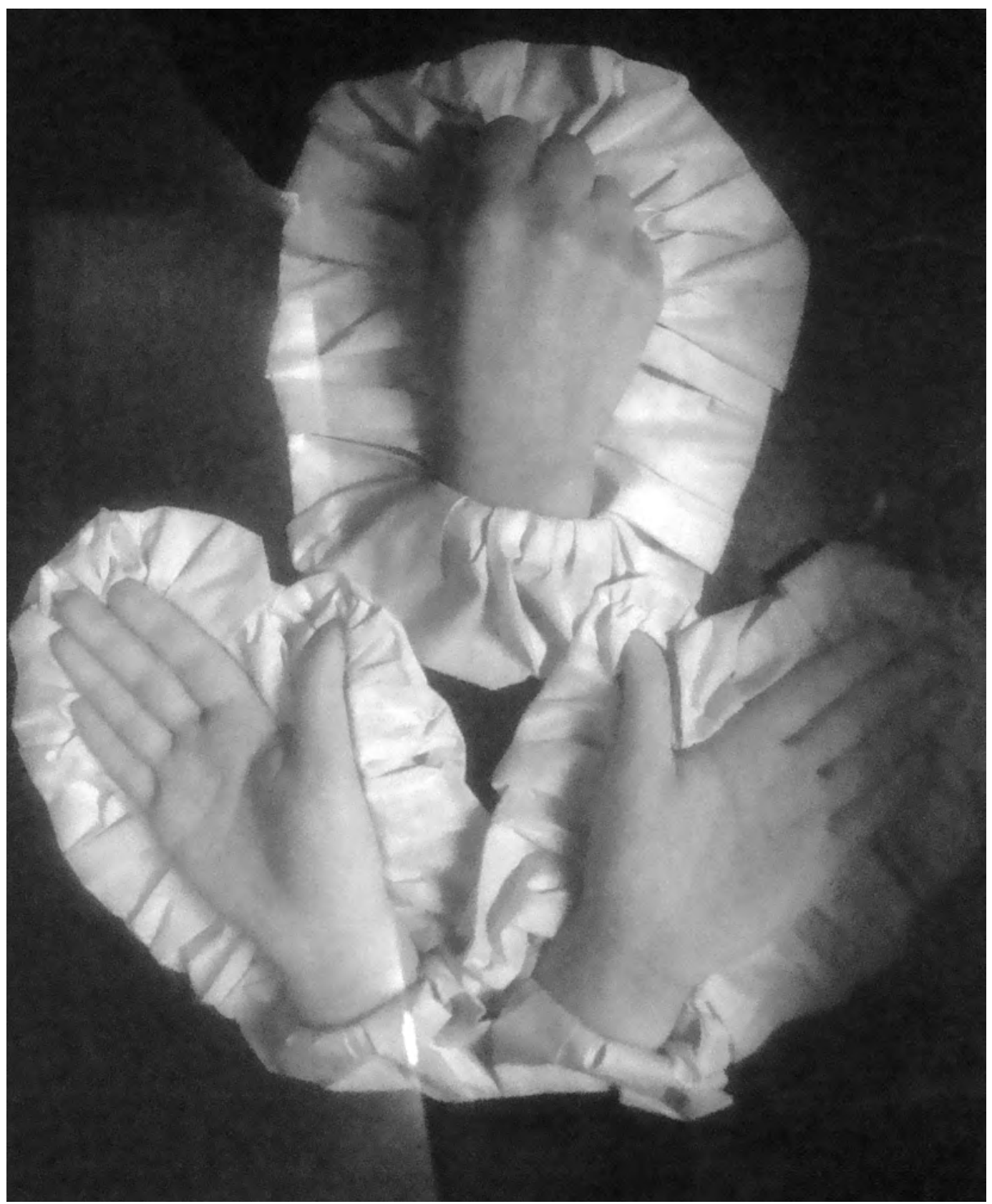

Figura 7: Características para a identificação do indivíduo (Museu Técnico-científico do Instituto Oscar Freire/FMUSP; caixa 59; foto do autor) 


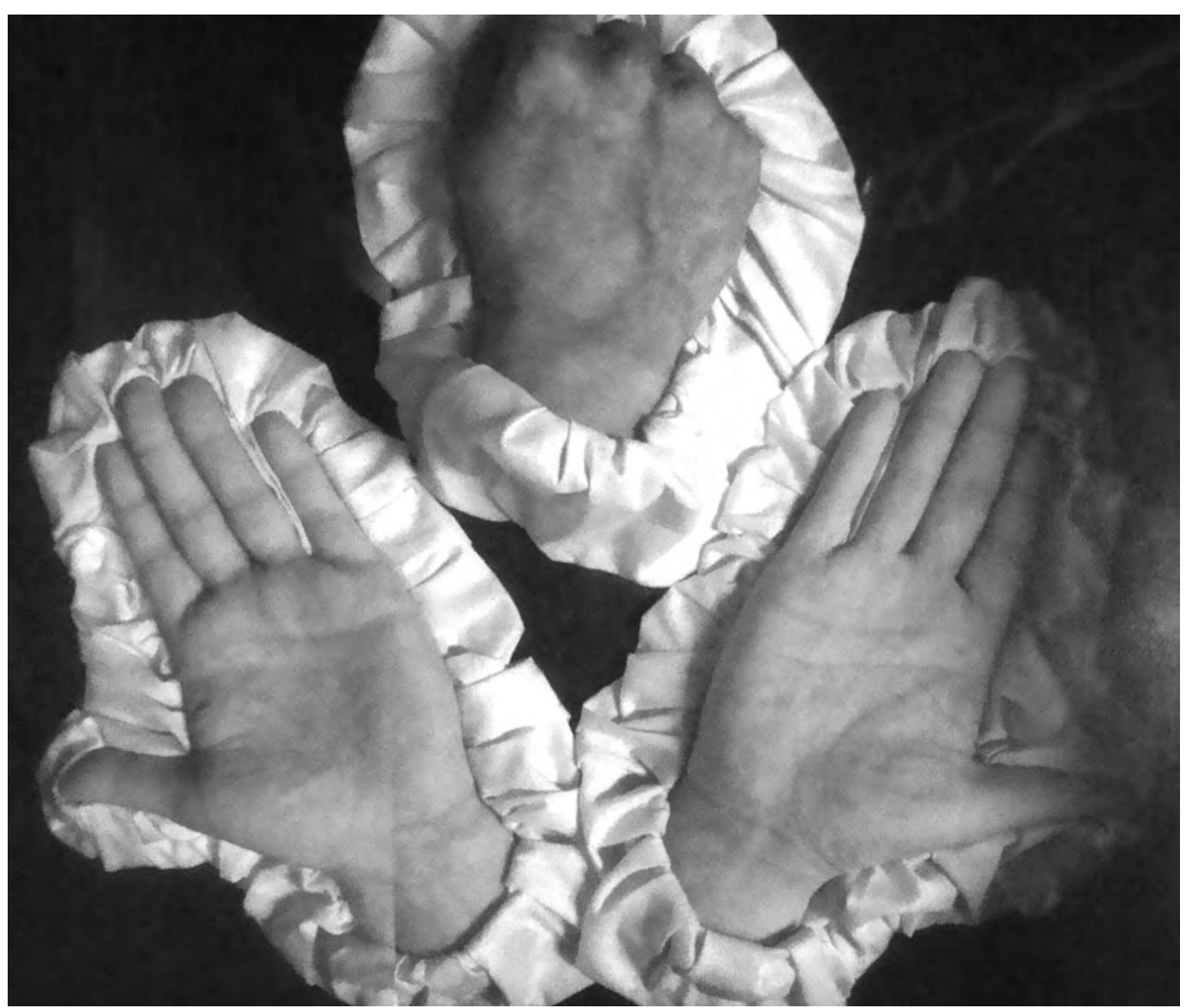

Figura 8: Características para a identificação do indivíduo (Museu Técnico-científico do Instituto Oscar Freire/FMUSP; caixa 58; foto do autor)

\section{Infortunística (acidentes de trabalho)}

A patologização do comportamento a que nos referimos (Ferla, 2005) se estendia ao ambiente de trabalho. Os acidentes sofridos pelos operários eram tidos como perturbadores da ordem racional da fábrica e tornaram-se uma das grandes preocupações da medicina legal. O acervo ceroplástico do Museu Técnico-científico do Instituto Oscar Freire contém peças que atestam essa preocupação. Elas fixavam as lesões e o tratamento dado a elas, como se pode constatar na Figura 9.

Pode-se ver a mutilação do dedo médio, provavelmente causada por máquina. Observa-se também a técnica cirúrgica utilizada para a reconstrução do coto e da pele. Outra representação de lesão ocupacional pode ser vista a seguir. Não há indicação de como ocorreu e nem do local onde o paciente trabalhava. Pode-se supor que a lesão tenha sido provocada por máquina industrial (Figura 10).

A ceroplastia também documentava as lesões causadas pelo esforço repetitivo, resultado da ocupação do indivíduo. Esse tipo de lesão pode ser visto na Figura 6 (estigma profissional do sapateiro). 


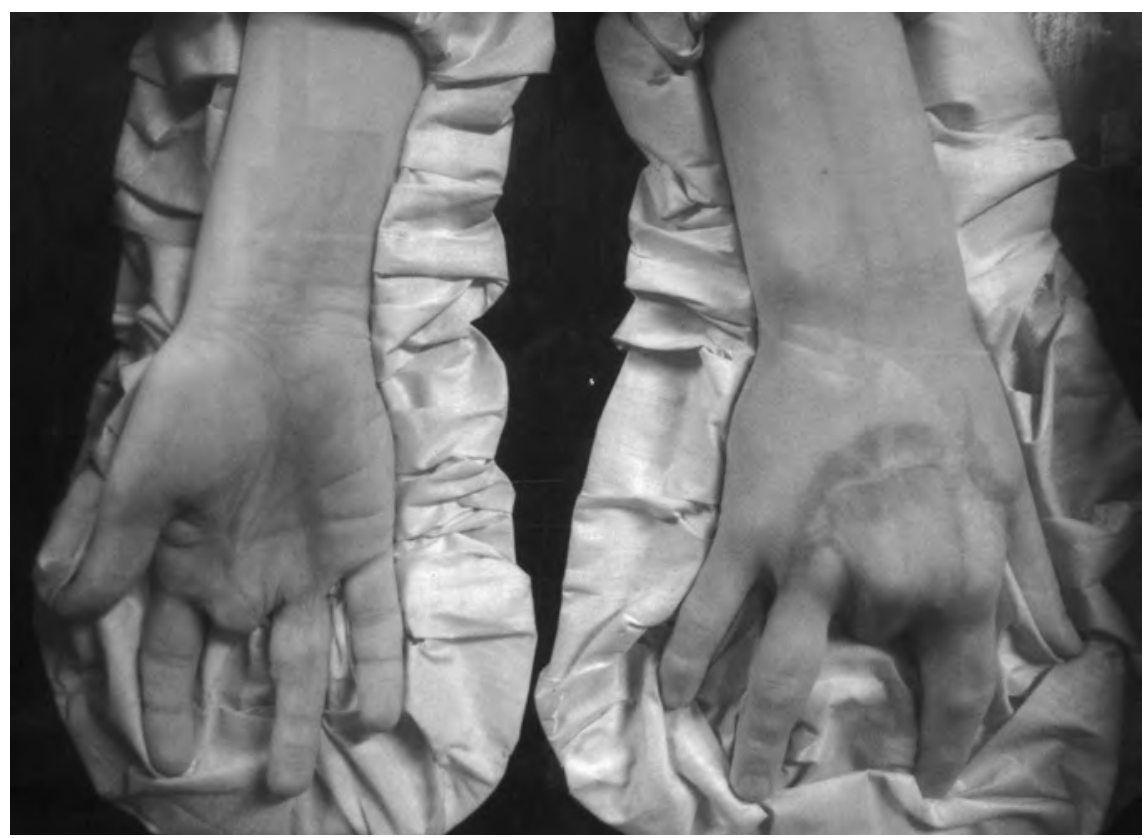

Figura 9: Acidente de trabalho: coto do dedo médio. Instituto Oscar Freire, Departamento de Medicina Legal, laudo 5.417/ F5.819 (Museu Técnico-científico do Instituto Oscar Freire/FMUSP; foto do autor)

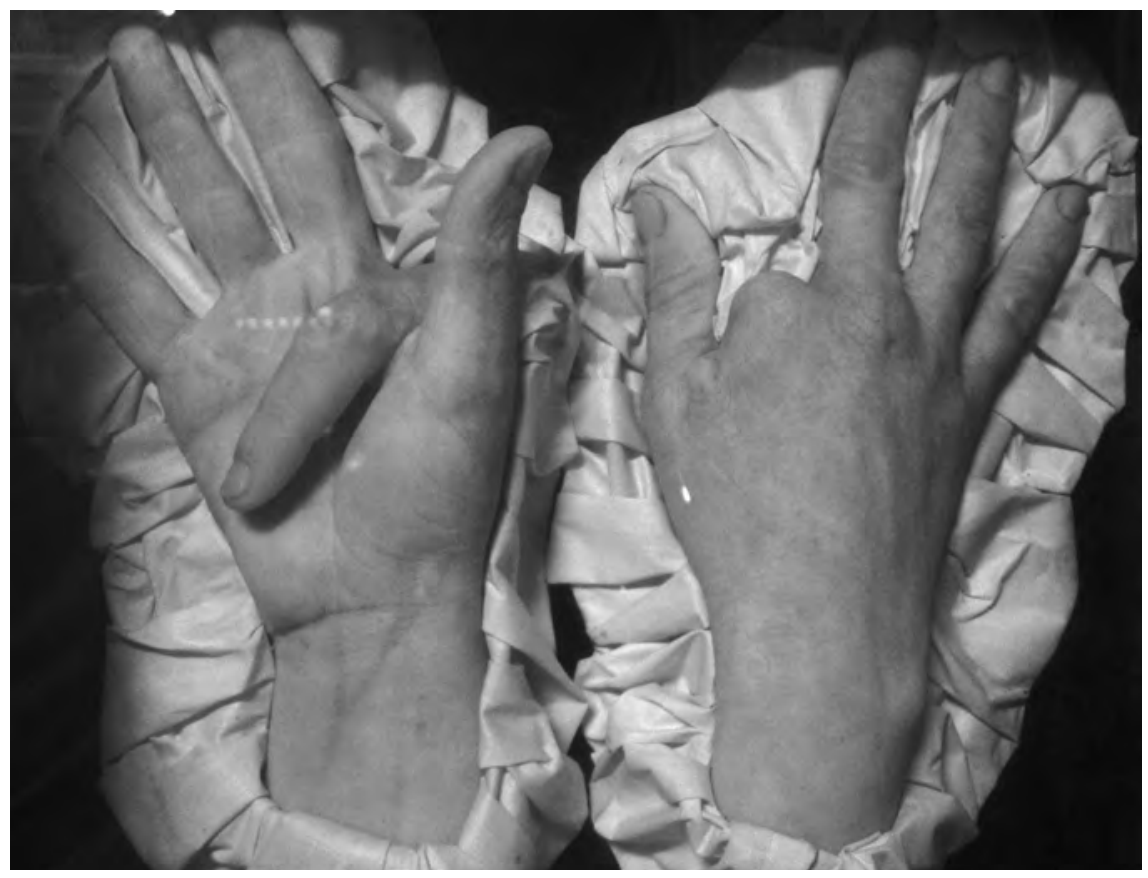

Figura 10:

Acidente de

trabalho: desvio

do dedo indicador direito para a região hipotênar (Museu Técnicocientífico do Instituto Oscar Freire/FMUSP; foto do autor)

\section{Sexologia (defloramentos e sífilis)}

A outra vertente de atuação da medicina legal paulista se referia aos exames de hímen. Como aponta Antunes (1999), um dos motivos desse tipo de exame estava relacionado aos casos de defloramento. Invocando o artigo 219 do Código Penal de 1916, muitos homens 
mal venéreo, era uma questão de polícia. Uma das formas de disseminação dessa doença estava relacionada à prostituição, assunto da alçada policial, embora tal prática não fosse tipificada como crime. Para a medicina legal, tratava-se de ato antissocial que deveria ser conhecido, o que possibilitaria desenvolver métodos preventivos. E, como indicamos, havia uma interação considerável entre a medicina legal paulista e os serviços policiais, vislumbrada pelo papel desempenhado pelos médicos no trabalho das identificações médico-legal e judiciária.

Em segundo lugar, a sífilis também era um tema da infortunística. De acordo com o livro publicado por Afrânio Peixoto e Flamínio Fávero (Peixoto et al., 1934, p.231-232), a sífilis podia também ser um acidente de trabalho ou doença ocupacional. No caso dos trabalhadores da indústria de vidro, o mal poderia ser transmitido por meio dos sopradores, instrumento indispensável nessa profissão. Essa seria a "sífilis-acidente".

A sífilis causava outra alteração no mundo do trabalho. Os operários portadores da doença que sofriam algum tipo de traumatismo demoravam mais para se reestabelecer e voltar às

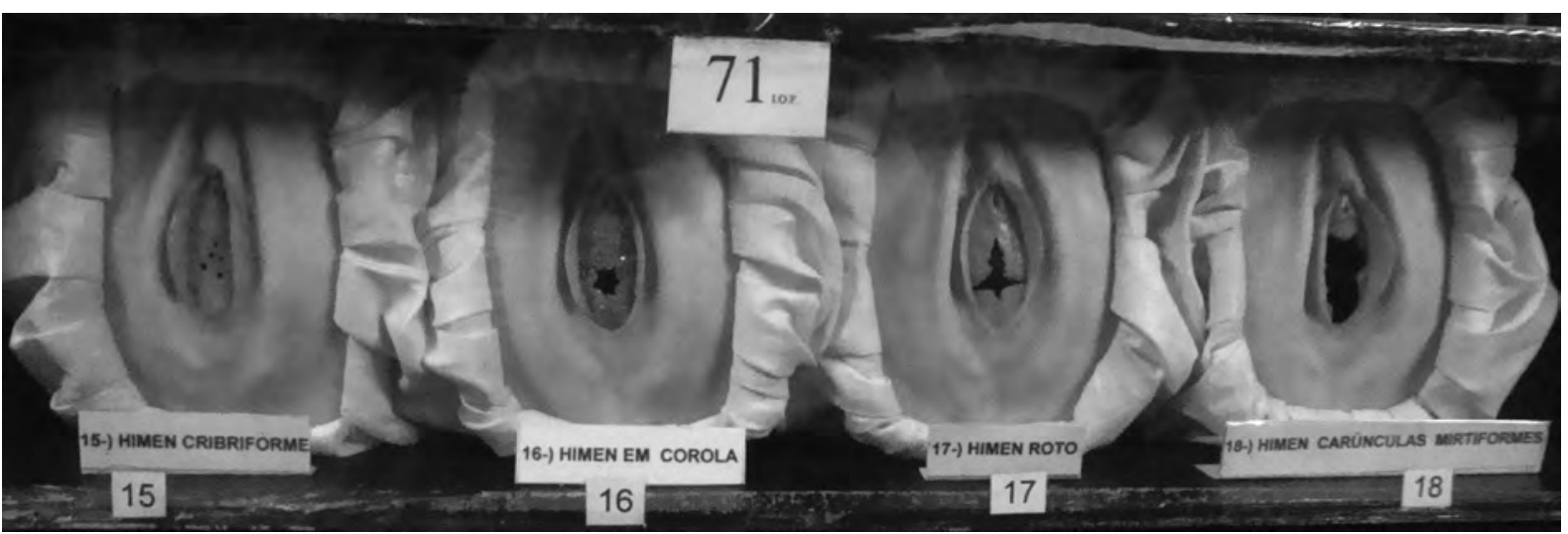

Figura 12: Tipos de hímen (Museu Técnico-científico do Instituto Oscar Freire/FMUSP; caixa 71, foto do autor)

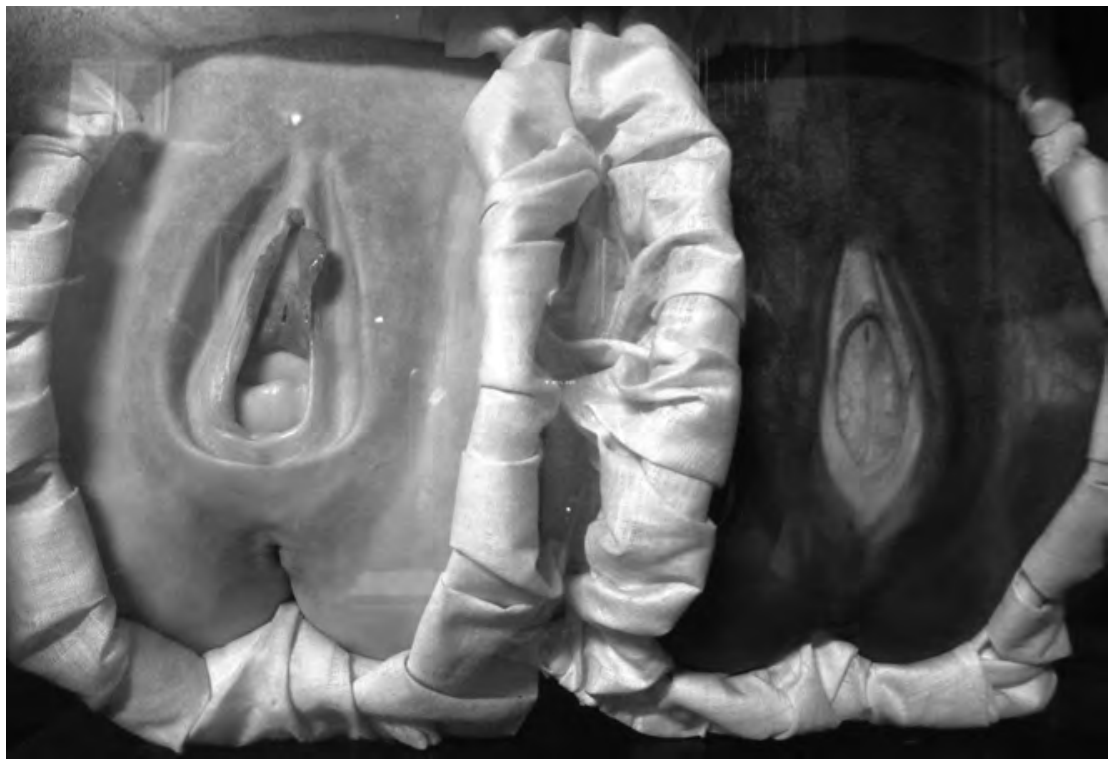

Figura 13: À esquerda, pele branca: ausência congênita de hímen, 17 anos. Observação do Instituto Oscar Freire, abr. 1939. À direita, pele negra: hímen imperfurado, 17 anos. Observação do Serviço de Ginecologia da Maternidade do Recife, mar. 1939 (Museu Técnicocientífico do Instituto Oscar Freire/FMUSP; caixa 72 ; foto do autor) 


\section{Considerações finais}

Procuramos demonstrar neste artigo como as peças ceroplásticas tiveram importante papel na definição do escopo da medicina legal paulista. As peças cobrem quase todos os temas que exigem a atuação do médico como perito. O tema genérico da qualidade da perícia médica em diversas áreas, mas sobretudo nos processos criminais, está entre aqueles sugeridos para Primeira Conferência Paulista de Medicina Legal e Criminologia, realizada em 1922. Alguns temas escolhidos para esse evento refletem a preocupação com uma disciplina ainda em formação e com a qualidade da perícia médica. São eles: (1) "a organização da perícia médica no processo criminal de modo a conceder-lhe o máximo de eficiência prática"; (2) "a orientação que deve receber o ensino de medicina legal nas Faculdades de Medicina e Direito em nosso país"; (3) a "necessidade de institutos de pesquisa e estudos anexos aos serviços médicos-periciais. Esses institutos podem ser os em que se faz o ensino da medicina legal?" (Sociedade..., 1922, p.6). Tais questões mostram que a medicina legal ainda lutava para estabelecer seus objetos e delimitar seus espaços de atuação.

A partir da década de 1930, período em que as peças começam a ser produzidas por Augusto Esteves, assistimos à criação do Ministério do Trabalho (1930) e à constituição da Justiça trabalhista. Em 1932, surgem as Comissões Mistas de Conciliação, substituídas mais tarde pelas Juntas de Conciliação e Julgamento. A Justiça do Trabalho aparece na Constituição de 1934, ainda fora do âmbito do Poder Judiciário. A partir de 1941, ela é regulamentada e passa a integrar aquele poder. Contudo, desde meados dos anos 1930, os advogados e médicos debruçavam-se sobre as questões relativas ao mundo do trabalho, produzindo manuais e tratados sobre o assunto. A produção ceroplástica junta-se a esse esforço para tornar a infortunística um dos temas privilegiados da medicina legal.

Flamínio Fávero é, sem dúvida, um dos expoentes do esforço de consolidação da medicina legal paulista, tratando de coligir os escritos de Oscar Freire e publicá-los após sua morte. Ele mesmo se dedicou à tarefa de escrever um tratado de medicina legal que foi utilizado durante décadas pelos alunos de sua cátedra. Também publicou numerosos artigos sobre os diversos temas da medicina legal. Foi um dos fundadores da Sociedade de Medicina Legal e Criminologia de São Paulo - que presidiu a partir de 1937 -, diretor da Faculdade de Medicina entre 1937 e 1938, membro do Conselho Penitenciário desde 1926 e diretor do Departamento de Presídios do Estado de São Paulo entre 1943 e 1945 (Ferla, 2009, p.81). Além disso, foi o responsável pela contratação do ceroplasta Augusto Esteves para o Departamento de Medicina Legal.

Não há indicação clara sobre todas as formas de utilização das peças, mas sabe-se que seu fim primordial era didático. ${ }^{22}$ Durante vários anos, elas serviram ao ensino nas cátedras de dermatologia e medicina legal. Augusto Esteves produziu outros tipos de material didático, tal como pranchas (desenhos e gravuras) para uso nas aulas de medicina legal. Há cerca de uma centena dessas pranchas sob guarda do Museu Técnico-científico do Instituto Oscar Freire.

Em 1980, por iniciativa de Carlos Silva Lacaz (1915-2002), diretor da Faculdade de Medicina entre 1974 e 1978 e idealizador do museu histórico, criou-se o Museu Ceroplástico Augusto Esteves, composto pelas peças produzidas na cátedra de dermatologia. Ele foi instalado em um dos saguões do Departamento de Microbiologia e Imunologia da Faculdade. A exposição foi 
desmontada anos depois, e as peças foram armazenadas por Lacaz no Museu da Faculdade de Medicina, onde ainda permanecem. Na década de 1990, foi produzido um vídeo sobre a obra de Augusto Esteves, idealizado por Lacaz e José Eduardo Costa Martins, naquele momento presidente da Sociedade Brasileira de Dermatologia. A obra foi financiada por um laboratório farmacêutico (Lacaz, 1993).

As peças revelam o intuito de intervenção na sociedade e expõem concretamente quais seriam os objetos dessa intervenção. Acreditamos que essa faceta da produção ceroplástica é até mais importante que seu uso didático ou museológico posterior. Mesmo tendo perdido seu papel didático e relegadas ao esquecimento, as peças ceroplásticas ganham hoje relevância dentro do campo da história da ciência. Como indicava Schnalke (1993, p.462) havia mais de uma década, as coleções ceroplásticas foram recuperadas e transformadas em objeto de estudo de historiadores da ciência e da medicina, que nelas viram importantes fontes para a compreensão da formação das especialidades médicas e da representação do corpo e de suas doenças.

\section{NOTAS}

${ }^{1}$ Entretanto, Foucault (2006, p.137) diz que no século XVIII a obtenção de cadáveres para dissecação tornouse mais fácil e os anatomistas trabalhavam tranquilamente.

${ }^{2}$ Segundo Ballestriero (2009, p.224), as primeiras tentativas de preservar cadáveres com injeções de produtos químicos foram feitas pelo italiano Marcello Malpighi (1628-1694) e pelo naturalista holandês Jan Swammerdam (1623-1680). Os preparados podiam ser coloridos ou não e continham elementos variados, como álcool, mercúrio, metais (chumbo, bismuto ou ferro) e cera.

${ }^{3}$ Canguilhem (2007, p.26) apontou as dificuldades dessa concepção. Mesmo negando o caráter "ontológico" das doenças e seu caráter qualitativo, o que impediria a nosografia de Phillipe Pinel e outros, Broussais ainda se apegava a uma definição "valorada" de estado normal, quer dizer, a um ideal de perfeição não claramente definido.

${ }^{4}$ De acordo com Foucault (2006, p.149), a anatomoclínica aplicou "o princípio diacrítico a uma dimensão muito mais complexa e problemática: aquela em que se articulam as formas visíveis da história patológica [sintomas] e os elementos visíveis que aparecem quando ela acaba".

${ }^{5}$ Gaetano Giulio Zumbo (1656-1701), treinado na Escola de Anatomia de Bolonha, teria trabalhado em Florença sob a proteção da família Médici. De formação religiosa (era um abade), suas primeiras obras em cera tinham caráter marcadamente religioso, mas o reconhecimento veio pelos chamados "Teatros da Morte" (ou "Teatrini"), que expressavam a decadência do corpo, o senso de precariedade da vida e a morte. Para mais detalhes, ver Poggesi (2006).

${ }^{6}$ Como assinalam os autores, ao final do século XIX, todos os grandes centros de dermatologia (Paris, Londres, Viena) possuíam importantes museus ceroplásticos. A coleção parisiense serviu de modelo para os demais hospitais dermatológicos europeus (Haviland, Parish, 1970, p.69).

${ }^{7}$ De acordo com Schnalke (1992), a coleção de moulages do Hôpital Saint Louis é a maior do mundo, contando com mais de quatro mil peças.

${ }^{8}$ Cf. Schnalke (1992, p.137): "Vários representantes da jovem disciplina reconheceram a vivacidade das moulages, que deixaram uma duradoura lembrança na memória dos observadores. Eles aceitaram a moulage como um meio 'moderno' de ensino da dermatologia, que superava a abstração bidimensional das ilustrações planas. Muitos dermatoveneorologistas deixaram Paris com a aspiração de organizar coleções de moulages nos hospitais de seus países de origem" (tradução do autor; destaque no original).

${ }^{9}$ Os modelos feitos de plástico, por exemplo, podiam ser reproduzidos diversas vezes a partir de um negativo. Eram mais resistentes, flexíveis e duradouros, além de apresentar cores mais fidedignas. Mas mesmo eles não resistiram ao desenvolvimento da fotografia dermatológica (Schnalke, 1993).

${ }^{10}$ Entre os pontos mais importantes desse modelo, podem-se destacar: a limitação do número de alunos por turma, ensino em tempo integral, a organização das disciplinas em departamentos e a vinculação do ensino clínico à estrutura do hospital escola (Mota, Schraiber, 2009, p.347). Sobre a atuação da Fundação Rockefeller na FMUSP, ver Marinho (2001). 
${ }^{11}$ A coleção ceroplástica da USP não é a única no Brasil. No Memorial da Medicina de Pernambuco, vinculado à Universidade Federal de Pernambuco, encontram-se em exposição 36 peças representando lesões dermatológicas e uma reproduzindo tipos de hímen. A autoria é desconhecida, mas é provável que o autor seja o próprio Augusto Esteves. Em sua autobiografia, constante nos arquivos do Museu Histórico da FMUSP, ele menciona que possui trabalhos em cera feitos para a Faculdade de Direito do Recife, de onde veio parte das peças do acervo atual do Memorial pernambucano. Para mais informações sobre a descrição das peças do Recife, ver Nascimento et al. (2012). Agradecemos a Emanuela Souza Ribeiro, coordenadora do Memorial da Medicina de Pernambuco, as informações prestadas.

${ }^{12}$ Seu trabalho no Butantan consistia em produzir desenhos (ilustrou o livro de Vital Brasil A defesa conta o ofidismo) e moldes de cobras em cera. Insatisfeito com os modelos importados da Alemanha, considerados imperfeitos e frágeis, Brazil incumbiu Esteves de moldar as peças a serem usadas em ensino e pesquisa. Esteves casou-se com Alvarina, filha de Vital Brazil, em 1920, e seguiu o cientista quando este deixou o instituto Butantan e fundou o Instituto Vital Brasil em Niterói, Rio de Janeiro.

${ }^{13}$ Segundo Ribeiro (2001), o Instituto Pinheiros Produtos Terapêuticos S.A. foi criado em 1928 por médicos treinados no Instituto Butantan. Um dos fundadores, Mário Pereira, trabalhou com Vital Brazil em seu instituto em Niterói, assim como Esteves. O Instituto Pinheiros produzia vacinas e soros, inclusive antiofídicos, chegando a ser responsável por $80 \%$ do abastecimento do mercado nacional. Havia peças de cera de autoria de Esteves no instituto que se perderam quando uma empresa estrangeira o comprou.

${ }^{14}$ No entanto, o catálogo do Museu Técnico-científico do Instituto Oscar Freire relaciona pelo menos noventa peças ceroplásticas em seu acervo. Entre peças desaparecidas ou destruídas, supomos que a produção de Esteves tenha chegado a pelo menos uma centena.

${ }^{15}$ Como indica Ferla (2009, p.80), a disciplina de medicina legal foi inserida nos currículos das escolas médicas da Bahia e do Rio de Janeiro em 1832. A Bahia tornou-se a principal escola da disciplina no Brasil e referência obrigatória para as demais. Para detalhes sobre a escola baiana de medicina legal, ver Correa (1998).

${ }^{16}$ Em 1922, houve a Primeira Conferência Paulista de Medicina Legal e Criminologia. Em 1937 ocorreu a Primeira Semana Paulista de Medicina Legal. A Segunda Semana foi realizada três anos depois, em 1940.

${ }^{17}$ É importante ressaltar que a medicina legal paulista não se desenvolvia autonomamente. Além de suas claras influências baianas, proporcionadas pela vinda de Oscar Freire, havia a colaboração de importantes personagens cariocas, tais como Afrânio Peixoto e Leonídio Ribeiro. Juntamente com os dois últimos, Flamínio Fávero publicou, em 1926, Medicina legal dos acidentes de trabalho e das doenças profissionais, obra que sugere a convergência, ainda que não absoluta, entre a medicina legal paulista e a carioca. Os problemas em discussão eram bastante semelhantes, assim como as soluções propostas. $\mathrm{O}$ tratado sobre a medicina do trabalho atesta, ainda que restrito a um dos muitos terrenos de intervenção da medicina legal, o esforço de cariocas e paulistas para atribuir caráter genuinamente nacional ao campo médico-legal. De acordo com Bertolli Filho (1993, p.38), a obra fixou "as bases nacionais da infortunística".

${ }^{18}$ Antunes (1999, p.21) chama atenção para a dificuldade de estabelecer esquematicamente as fases da evolução da medicina legal no Brasil. Souza Lima, enquadrado no segundo momento da evolução da medicina legal, morreu vinte anos depois de Nina Rodrigues, representante da terceira fase.

${ }^{19}$ De acordo com Salla e Marinho (2008), a medicina legal tornou-se uma especialidade médica madura e plenamente constituída na década de 1940.

${ }^{20}$ As imagens a seguir foram feitas pelo próprio autor a partir do acervo do Museu Técnico-científico do Instituto Oscar Freire da FMUSP. As peças, algumas com mais de 70 anos, encontram-se acondicionadas em caixas de madeira fechadas por um vidro. Não é possível retirar as peças e fotografá-las separadamente, sob pena de danificá-las. Assim, as fotos foram tiradas com o vidro, o que prejudicou um pouco a resolução das imagens. As legendas reproduzem as placas descritivas dentro das caixas, além da numeração e data, quando indicadas. Não há prontuários de pacientes acompanhado as peças. Algumas trazem o nome do paciente e do prontuário, outras se limitam à descrição da lesão representada.

${ }^{21}$ Havia uma profunda identificação entre a medicina legal e a atividade policial no Brasil. O Congresso Nacional de Identificação, de 1934, ocorreu na sala das sessões da Faculdade de Medicina de São Paulo. Nele se discutiu a necessidade de se estabelecerem formas de identificação dos indivíduos, a instalação de laboratórios de antropologia criminal e a formação de um corpo técnico, versado no conhecimento da medicina legal, para atuar na resolução dos crimes (Conclusões..., abr. 1936, p.165-169).

22 Em 1948, na Quarta Semana Paulista de Medicina Legal, Augusto Esteves defendeu que as peças ceroplásticas poderiam ser exibidas como provas durante o julgamento de processos criminais. Dizia ele que era "perfeitamente justo que as moldagens, do ponto de vista de documentação para fins judiciários 
tenham um papel relevante e ímpar como elemento de prova e convicção" (Esteves, 1950, p.238). Contudo, não encontramos nenhuma indicação de que as peças tenham sido realmente utilizadas em processos criminais.

\section{REFERÊNCIAS}

ANTUNES, José Leopoldo Ferreira.

Medicina, leis e moral: pensamento médico e comportamento no Brasil (1870-1930). São Paulo: Edunesp. 1999.

BALLESTRIERO, Roberta.

Anatomical models and wax Venuses: art masterpieces or scientific craft works? Journal of Anatomy, v.216, n.2, p.223-234. 2009.

BERNARD, Claude.

Introducción al estudio de la medicina experimental. Buenos Aires: Losada. 1944.

BERTOLLI FILHO, Claudio.

Medicina e trabalho: as "ciências do comportamento" na década de 40. Revista de História, n.127-128, p.37-51. 1993.

CANGUILHEM, Georges.

O normal e o patológico. Rio de Janeiro: Forense Universitária. 2007.

CONCLUSÕES...

Conclusões aprovadas pelo Congresso Nacional de Identificação. Arquivos de Polícia e Identificação, n.1, p.165-169. abr. 1936.

CORRÊA, Mariza.

As ilusões da liberdade: a escola Nina Rodrigues e a antropologia no Brasil. Bragança Paulista: Edusf. 1998.

ESTEVES, Augusto.

Das moldagens a serviço da medicina legal e da justiça. In: Sociedade de Medicina Legal e Criminologia de São Paulo. Semana Paulista de Medicina Legal da Sociedade de Medicina Legal e Criminologia de São Paulo. São Paulo: Tipografia do Departamento de Investigações. p.237-239. 1950.

FÁVERO, Flamínio.

Medicina legal. São Paulo: Martins Fontes. 3v. 1958.

FÁVERO, Flamínio.

Memorial ao Colendo Conselho TécnicoAdministrativo da Faculdade de Medicina da Universidade de São Paulo, 10 out. 1940. Fundo Flamínio Fávero (1895-1982), caixa CTx-01 (Museu Histórico da Faculdade de Medicina da Universidade de São Paulo, São Paulo). 10 out. 1940.

FÁVERO, Flamínio.

Classificação de Oscar Freire para as formas himenais. Revista de Criminologia e Medicina Legal, separata. 1930.

FERLA, Luis.

Feios, sujos e malvados sob medida: a utopia médica do biodeterminismo, São Paulo (19201945). São Paulo: Alameda. 2009.

FERLA, Luis.

O trabalho como objeto médico-legal em São Paulo dos anos 1930. Asclepio, v.57, n.1, p.237263. 2005.

FOUCAULT, Michel.

O nascimento da clínica. Rio de Janeiro: Forense Universitária. 2006.

HAVILAND, Thomas N.; PARISH, Lawrence C. A brief account of the use of wax models in the study of medicine. Journal of the History of Medicine and Allied Sciences, v.25, n.1, p.52-75. 1970.

LACAZ, Carlos da Silva.

Museu ceroplástico Augusto Esteves (1891-1966). Revista da Sociedade Brasileira de Medicina Tropical, v.26, n.2, p.125-126. 1993.

LANDES, Joan B.

Wax fibers, wax bodies and moving figures: artifice and nature in eighteenth-century anatomy. In: Panzanelli, Roberta (Ed.). Ephemeral bodies: wax sculpture and the human figure. Los Angeles: Getty Research Institute. p.41-65. 2008.

MARINHO, Maria Gabriela S.M.C.

Norte-americanos no Brasil: uma história da Fundação Rockefeller na Universidade de São Paulo, 1934-1952. São Paulo: Autores Associados; Fapesp; Universidade São Francisco. 2001.

MEIRA, Affonso Renato; BATTISTELLA, Linamara Rizzo.

Departamento de Medicina Legal, Ética Médica e Medicina Social e do Trabalho. In: Mota, André; Marinho, Maria Gabriela S.M.C. Departamentos da Faculdade de Medicina de São Paulo: memórias e histórias, v.2. São Paulo: Faculdade de Medicina/ Universidade de São Paulo. p.108-123. 2012.

MONTEIRO, Marko.

Teatro anatômico digital: práticas de representação do corpo na ciência contemporânea. Trabalho apresentado no 33. Encontro Anual da Associação Nacional de Pós-graduação e Pesquisa em Ciências Sociais. Caxambu. 2009. 
MOTA, André; SCHRAIBER, Lilia Blima. Mudanças corporativas e tecnológicas da medicina paulista em 1930. História, Ciências, Saúde-Manguinhos, v.16, n.2, p.345-360. 2009.

NASCIMENTO, Cintia Rodrigues do et al. Diagnóstico de conservação da coleção de cera do Memorial de Medicina da UFPE. In: Encontro Nacional dos Estudantes de Museologia, 4., 2011, Goiânia. Sá, Aluane de; Montefusco, Hitalo; Boita, Tony (Org.). Anais... Goiânia: Digital Books. p.196-202. 2012.

PEIXOTO, Afrânio et al.

Acidentes de trabalho. Rio de Janeiro: Guanabara. 1934.

POGGESI, Marta.

A coleção de figuras em cera do museu La Specola. In: Lamers-Schutze, Petra; Havertz, Yvonne (Ed.). Encyclopaedia anatomica: Museu La Specola, Florence. Colônia: Taschen. p.46-61. 2006.

RIBEIRO, Maria Alice Rosa.

Saúde pública e as empresas químicofarmacêuticas. História, Ciências, Saúde Manguinhos, v.7, n.3, p.607-626. 2001.

SALLA, Fernando; MARINHO, Maria Gabriela S.M.C.

Medicina legal e perícias médicas em processos criminais. Constituição de saberes e aplicação de procedimentos médico-legais. Campo, personagens e práticas periciais: São Paulo e Bragança, 1890-1940. In: Encontro Regional de História, 19., 2008, São Paulo. Anais... São Paulo: Associação Nacional de História/SP; Universidade de São Paulo. (CD-ROM). 2008.
SAMPAIO, Sebastião de Almeida Prado, LACAZ, Carlos da Silva, AZULAY, Rubem David. In memoriam: Aguiar Pupo. Anais Brasileiros de Dermatologia, v.55, n.4, p.212-217. 1980.

SCHNALKE, Thomas.

Diseases in wax: the history of the medical moulage. Berlin: Quintessence. 1995.

SCHNALKE, Thomas.

A brief history of dermatologic moulage in Europe, part 3: prosperity and decline. International Journal of Dermatology, v.32, n.6, p.453-463. 1993.

SCHNALKE, Thomas.

A brief history of dermatologic moulage in Europe, part 2: breakthrough and rise. International Journal of Dermatology, v.31, n.2, p.134-141. 1992.

SCHRAIBER, Lilia Blima.

O médico e seu trabalho: limites da liberdade. São Paulo: Hucitec. 1993.

SEVALHO, Gil.

Uma abordagem histórica das representações sociais de saúde e doença. Cadernos de Saúde Pública, v.9, n.3, p.349-363. 1993.

SOCIEDADE...

Sociedade de Medicina e Criminologia de São Paulo. Primeira Conferência de Medicina Legal e Criminologia. São Paulo: Seção de Obras do Estado de São Paulo. 1922. 